\title{
Chronic Subdural Hematoma with Extracapsular Hemorrhage -Case Report-
}

\author{
Tetsuji ORITA, Kunihiko HARADA, Katsuhiro YAMASHITA, \\ Tomomi OKAMURA and Hideo AOKI
}

Department of Neurosurgery, Yamaguchi University School of Medicine, Ube, Yamaguchi

\begin{abstract}
An elderly male presented with the rarity of a chronic subdural hematoma accompanied by an extracapsular hemorrhage. A computed tomographic finding peculiar to this condition is the presence of a two-layer structure consisting of an inner high-density area and an outer low-density area. This feature and the possible mechanism of extracapsular hemorrhage are discussed.
\end{abstract}

Key words: chronic subdural hematoma, extracapsular hemorrhage, computed tomography

\section{Introduction}

The coexistence of a chronic subdural hematoma and extracapsular hemorrhage appears to be extremely rare; we found only four cases reported in the literature. ${ }^{4,6,8,9)}$ In the three cases in which computed tomography (CT) was performed, the findings were similar to those we observed in our patient.

\section{Case Report}

A 66-year-old male who had stumbled and fallen subsequently suffered from gradually progressive vomiting and disturbed consciousness. Three days after the fall he was admitted to our hospital. His family averred that the patient had not struck his head at the time of the fall, but that he had occasionally complained of a sensation of heaviness in his head for 4 months prior to admission. There was no other documented history of head trauma or bleeding tendency.

On admission he was semicomatose, responding to deep painful stimuli with bilateral decerebrate posturing. The right pupil was $1 \mathrm{~mm}$ larger in diameter than the left and both pupils responded sluggishly to light. Babinski response was present bilaterally.

Skull x-rays were not obtained. Emergency CT without contrast medium showed a striking shift of the ventricular system from right to left. The cause of the shift was a right subdural hematoma, which was a two-layer structure having an inner highdensity area and an outer low-density area. A small region of low density was also noted in the left subdural space (Fig. 1). At this time, he was diagnosed as having a bilateral chronic subdural hematoma with apoplectiform onset.

He was immediately operated upon. Through a burr hole, the dura and the outer membrane of the hematoma capsule were incised, and about $40 \mathrm{ml}$ of xanthochromic fluid spurted out. At this point, since there was a substantial solid clot under the inner membrane of the hematoma capsule, the burr hole approach was abandoned in favor of a right frontoparietal craniotomy. After incision of the inner membrane, approximately $100 \mathrm{gm}$ of solid subdural clot was evacuated. No membrane was found under the clot. Neither cortical laceration nor subarachnoid hemorrhage was seen on the cortical surface. The source of bleeding was not identified, despite the wide field of exposure (Fig. 2).

Received November 19, 1986; Accepted August 10, 1987

Authors' present addresses: K. Yamashita, M.D., Department of Neurosurgery, Saiseikai Yamaguchi General Hospital, Yamaguchi, Japan; T. Okamura, M.D., Department of Neurosurgery, Ube Kosan Central Hospital, Ube, Yamaguchi, Japan. 


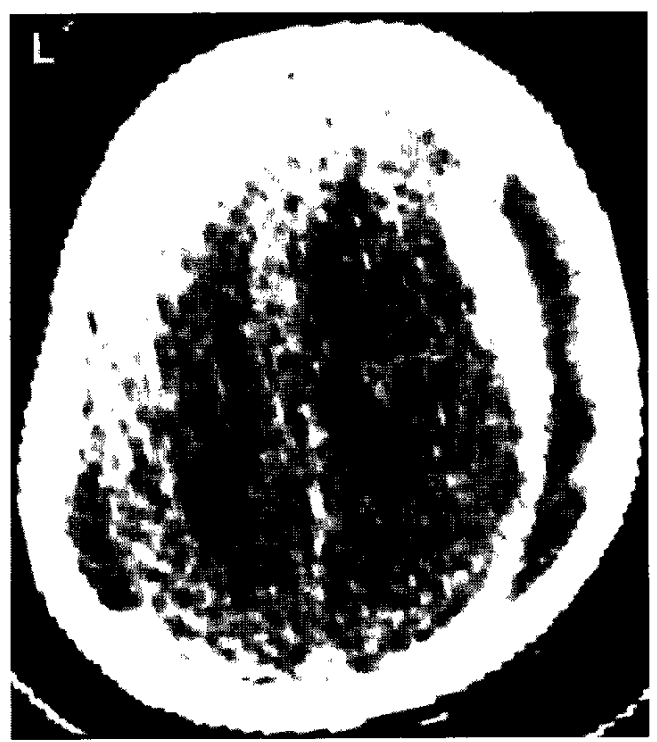

Fig. 1 Precontrast computed tomography showing a right subdural hematoma consisting of two layers, with a high-density area on the brain side and a low-density area on the bone side. A small low-density area is also seen in the left subdural space.

Histological examination showed the outer membrane to consist of well vascularized granulation tissue. The inner membrane was thinner and was composed of loose connective tissue with scant blood vessels. There were no abnormal vessels in either membrane.
He slowly improved, and on postoperative day 7 responded to simple verbal commands. Postoperative CT showed both sides to be free of subdural hematoma. However, he developed a severe respiratory infection, hypernatremia, and hyperglycemia, all of which had existed preoperatively, and on the 17th postoperative day he died. Permission for autopsy was not obtained.

\section{Discussion}

Chronic subdural hematoma accompanied by extracapsular hemorrhage is apparently very rare. Among the four cases reported to date ${ }^{4,6,8,9)}$ (Table 1), the first, described by Isu et al.,6) was a subacute subdural hematoma surrounding a calcified subdural hematoma. However, CT was not performed. In the other three cases, ${ }^{4,8,9)} \mathrm{CT}$ scans were obtained, and the findings were similar to those in our patient that is, in each instance there was a two-layer structure consisting of a high-density area on the brain side and a low-density area on the bone side. The importance of this consistent feature, which has not so far been emphasized, is that the presence of bilateral subdural hematomas, as seen in our case, will almost invariably be interpreted as a mixed-type chronic subdural hematoma.

The mixed-type chronic subdural hematoma is characterized by heterogeneity in terms of $x$-ray attenuation. A combination of low and high density prevails. Usually the frontal portion of the hematoma is of low density, while the posterior
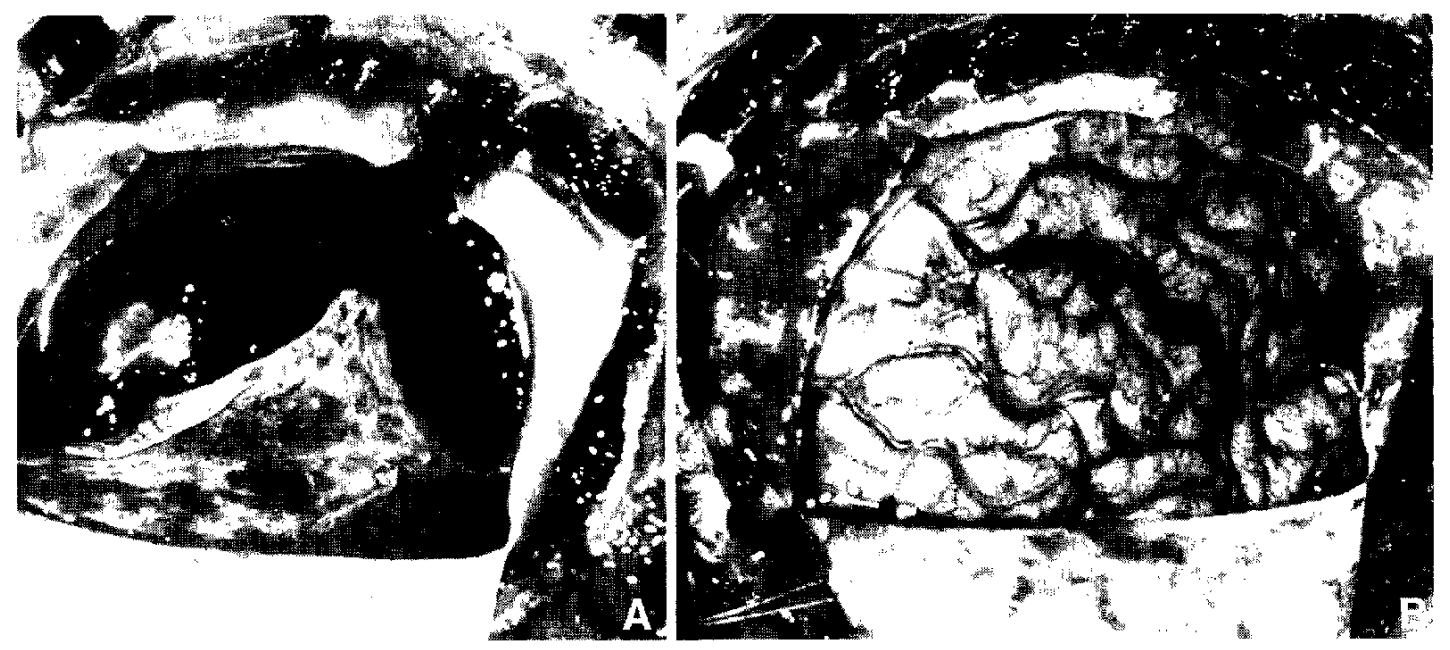

Fig. 2 A: Intraoperative photograph showing solid clots under the inner membrane of the chronic subdural hematoma. The dura mater and outer membrane can be seen in the lower part of photograph. B: Neither cortical laceration nor subarachnoid hemorrhage is evident on the cortical surface. 
Table 1 Reported cases of chronic subdural hematoma with extracapsular hemorrhage

\begin{tabular}{|c|c|c|c|c|c|}
\hline $\begin{array}{l}\text { Case } \\
\text { No. }\end{array}$ & Author (Year) & $\underset{\text { Sex }}{\text { Age/ }}$ & CT finding & $\begin{array}{l}\text { Hematoma } \\
\text { contents }\end{array}$ & $\begin{array}{l}\text { Source of } \\
\text { bleeding }\end{array}$ \\
\hline 1 & Isu et al. $(1977)^{6)}$ & $45 / M$ & CT not performed & calcified mass; clot & adhesion \\
\hline 2 & $\underset{(1982)^{4)}}{\text { Hasegawa et al. }}$ & $48 / F$ & two-layer structure & fluid; clot & superficial artery \\
\hline 3 & $\underset{(1982)^{8)}}{\text { Matsumura et al. }}$ & $82 / F$ & two-layer structure & fluid; clot & unknown \\
\hline 4 & $\begin{array}{l}\text { Matsumura and Nojiri } \\
(1984)^{9)}\end{array}$ & $57 / \mathrm{F}$ & two-layer structure & thick membrane; clot & anastomotic vessel \\
\hline 5 & Present case & $66 / \mathrm{M}$ & two-layer structure & fluid; clot & unknown \\
\hline
\end{tabular}

${ }^{*}$ Bone side; brain side.

region is of high density, ${ }^{3}$ and these two compartments may be sharply demarcated. In this type of hematoma there has been fresh bleeding into a preexisting chronic subdural hematoma, accompanied by clinical deterioration. ${ }^{2,3)}$ However, a mixed-type chronic subdural hematoma having a two-layer structure of high inner density and low outer density has never been reported. ${ }^{1-3,7)}$ We conclude that this finding is specific to extracapsular hemorrhage. It is important, in the interest of appropriate clinical management, to be aware of this difference.

In the case reported by Isu et al., ${ }^{6)}$ the source of bleeding, which was identified during surgery, was a network of abundant, fine vessels lying between the calcified subdural hematoma and the cortical surface. In Hasegawa's case, ${ }^{4)}$ evacuation of an acute subdural hematoma disclosed bleeding from a branch of the cortical artery. In Matsumura's $\mathrm{s}^{9)}$ patient, who had moyamoya disease, bleeding occurred from a transdural cortical anastomosis of the middle meningeal artery. The source of bleeding was not discovered in the third case. ${ }^{8)}$

In our case, angiography was not performed and the origin of the hemorrhage was not identified in surgery, so we were unable to definitely establish the mechanism by which the extracapsular hemorrhage occurred. However, we think that the mechanism was similar to that of acute "spontaneous" subdural hematoma. ${ }^{10)}$ Briefly, development of a chronic subdural hematoma leads, in some instances, to the formation of significant adhesions between the surface of the brain and the inner membrane. ${ }^{5)}$ Any sudden movement of the head would apply tension to these adhesions, some of which are attached to the wall of a vessel on the surface of the brain, and it is conceivable that they might be torn in this way. In this case the hematoma could extend to the space between the inner membrane of the hematoma capsule and the surface of the brain. Hypertension, arteriosclerosis, and brain atrophy also may be important contributory factors.

\section{Acknowledgment}

The authors would like to thank Dr. Toshifumi Kamiryo and Miss Y. Ichimura, Department of Neurosurgery, Yamaguchi University School of Medicine, for their assistance in the preparation of the manuscript.

\section{References}

1) Forbes GS, Sheedy PF II, Piepgras DG, Houser OW: Computed tomography in the evaluation of subdural hematomas. Radiology 126: 143-148, 1978

2) French BN, Dublin AB: The value of computerized tomography in the management of 1000 consecutive head injuries. Surg Neurol 7: 171-183, 1977

3) Grumme TH, Lanksch W, Aulich A: The diagnosis of chronic subdural hematoma by computed axial tomography, in Lanksch W, Kazner E (eds): Cranial Computed Tomography. Berlin, Springer, 1976, pp 337-341

4) Hasegawa $\mathbf{H}$, Bitoh S, Fujiwara $M$, Nakata $M$, Oku Y, Ozawa E, Taneda M: Subdural hematoma from arterial rupture. Mechanism of arterial rupture in minor head injury. No Shinkei Geka 10: 839-846, 1982 (in Japanese)

5) Hirano A: An Outline of Neuropathology, ed 1. Tokyo, Igaku-Shoin, 1976, pp 210-214

6) Isu $T$, Takamura $H$, Ueno $K$, Hirama $M$ : A case of subacute subdural hematoma associated with a calcified subdural hematoma. No Shinkei Geka 5: 1279-1283, 1977 (in Japanese)

7) Markwalder TM: Chronic subdural hematomas: A review. I Neurosurg 54: 637-645, 1981

8) Matsumura M, Kawano K, Tanaka S, Ishii Z: A case of chronic subdural hematoma with extracapsular hemorrhage. Proceedings of the 5th Conference of Japanese Society of Neurotraumatology. 1982, p 291

9) Matsumura M, Nojiri K: Resolved chronic subdural hematoma associated with acute subdural hematoma 
in moyamoya disease. Case report. Neurol Med Chir (Tokyo) 24: 622-627, 1984 (in Japanese)

10) Talalla A, Mckissock W: Acute "spontaneous" subdural hemorrhage: An unusual form of cerebrovascular accident. Neurology (Minneap) 21: 19-25, 1971
Address reprint requests to: T. Orita, M.D., Department of Neurosurgery, Yamaguchi University School of Medicine, 1144 Kogushi, Ube, Yamaguchi 755, Japan. 